\title{
Performance of wire rope isolators in the seismic protection of equipment
}

\author{
Moussa Leblouba ${ }^{1,{ }^{*}}$ and Samer Barakat ${ }^{1}$ \\ ${ }^{1}$ University of Sharjah, Department of Civil \& Environmental Engineering, P.O.BOX 27272, \\ University City, Sharjah, United Arab Emirates
}

\begin{abstract}
Different isolation systems are currently employed to protect sensitive equipment and their hosting structures from undesirable vibrations originating from earthquake ground motions. Wire rope isolator (WRI), a type of passive isolator is known to be effective in isolating the vibrations and shock, can be used for vibration isolation of structures and equipment. The aim of the present work is to study the performance of WRIs in mitigating the vibrational response of equipment mounted on the upper floor of a multi-story structure using numerical simulations. In multistoried buildings, the upper floors experience significantly amplified accelerations than the lower floors and hence the sensitive equipment requires an effective vibration isolation system. The present study shows that the WRI can provide an effective isolation by reducing the equipment acceleration through its lateral flexibility while satisfying the displacement demand. The Performance of the WRI was assessed considering six different earthquake excitations in a series of numerical simulations. The influence of flexibility of the structure on the performance of the WRI is also reported.
\end{abstract}

\section{Introduction}

The vibrations from the sources such as an earthquake or due to operations of heavy machineries can affect the functionality and cause structural damage to the structures and surrounding equipment. This signifies the application of vibration isolators to isolate the system from the vibration environment [1-4]. In general, the mitigation of vibrational response of the equipment and structures can be performed through three approaches $[5,6]$ : (1) Isolation of the entire housing structure, (2) isolation of single equipment, (3) isolation of raised-floor system. The first approach is suitable for new construction where isolators are installed between the structure and foundation to reduce the damage to both primary structure and equipment [7]. The second approach concentrates only on the equipment; the isolation system is inserted at the base of the equipment to reduce the transmission of vibration. However, both the approaches are confronted with a difficulty to achieve the desired long period within an affordable displacement [8].

\footnotetext{
* Corresponding author: mleblouba@,sharjah.ac.ae
} 
In the third approach, the equipment is fixed to a secondary floor, which decouples from the structural floor by an isolation system consisting of several isolators. This approach provides the potential benefit to both new and existing constructions. Raised floor approach also possesses advantages such as low cost when compared with first approach and it can also provide long period while maintaining the affordable displacements [3,9]. Therefore, raised floor approach is well-established as an effective technique for the vibration mitigation of equipment [6], hence, the present work focuses on the third approach. Different types of passive isolation devices are used and they can be broadly categorized as linear and non-linear isolators. Linear vibration isolators are useful only if the excitation frequencies are higher than their natural frequency. Hence, their application is limited to moderate environmental disturbance [2]. This limitation can be overcome by using non-linear vibration isolators [2]. Several researchers have developed different types of nonlinear vibration isolators and have investigated their unique dynamic behaviors. A detailed survey on the developments of nonlinear vibration isolators is provided by Ibrahim [2], in which many cited studies [10-11] reveals that the introduction of nonlinear damping and nonlinear stiffness is of great benefit in vibration isolation. Recently, Wire Rope Isolators (WRI), a type of passive vibration isolation which exhibits non-linear behavior, has become the subject of intensive studies [12-17].

\section{Modeling of WRI in shear}

The geometrical characteristics and specification of the WRI used in this study are shown in Figure 1 and Table. 1 respectively. The test results showed that the WRI exhibits nonlinear hysteresis behavior when subjected cyclic shear loading (Figure 2). This type of behavior is simulated using the Bouc-Wen model of hysteresis [8, 12, 18-19]. The BoucWen model is the first-order nonlinear differential algebraic equation, which hysterically relates the input displacement and the output restoring force, its general form is given by:

$$
F=a \frac{F_{y}}{x_{v}} x+(1-\alpha) F_{y^{2}}
$$

where $F$ is the restoring force, $x$ is the displacement, $F_{y}$ is the yield force, $x_{y}$ is the yield displacement and $z$ is a dimensionless hysteresis quantity in the range of $[-1,+1]$ and is given by:

$$
x_{y} \dot{z}=A \dot{x}-\left\{\beta|\dot{x}| z|z|^{n-1}+\gamma \dot{x}|z|^{n}\right\}
$$
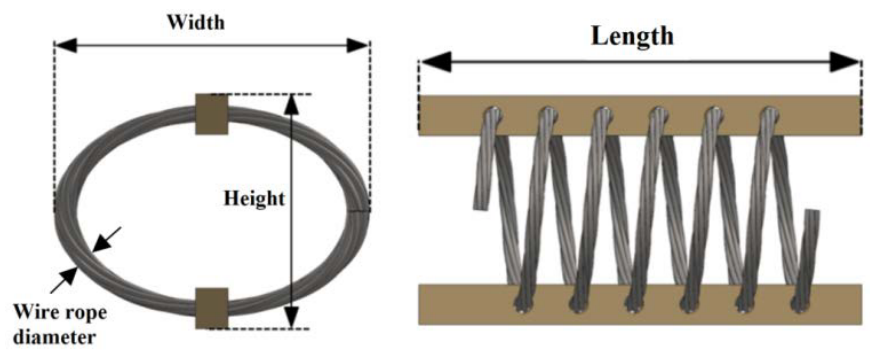

Fig. 1. Geometry of the wire rope isolator.

The dimensionless parameters $A, \beta, \gamma$, and $n$ control the shape of the hysteresis loop. The above hysteresis model is implemented in SAP2000 ${ }^{\circledR}$ program as the Plastic Wen NLLink element, which is recommended for $2 \mathrm{D}$ static and dynamic analysis. The parameters of the Bouc-Wen model were used to mathematically define the behavior of the WRI in the 
simulation model to determine the response. The parameters of the Bouc-Wen model were determined using the Least-Squares method (Table. 1). Figure 2 shows that the Bouc-Wen model with the identified parameters can predict, with enough accuracy, the experimental force-displacement relationship.

Table 1. Geometrical characteristics and Bouc-wen parameters of the WRI used in the present study.

\begin{tabular}{|c|c|}
\hline \multicolumn{2}{|c|}{ Geometrical characteristics } \\
\hline Wire rope Diameter & $9.5 \mathrm{~mm}$ \\
\hline Length of WRI & $215 \mathrm{~mm}$ \\
\hline Width of WRI & $105 \mathrm{~mm}$ \\
\hline Height of WRI & $76 \mathrm{~mm}$ \\
\hline Number of Turns & 8 \\
\hline Bouc-Wen Parameters \\
\hline Loading direction & Lateral \\
\hline$x_{\mathrm{y}}$ & $0.433 \mathrm{~mm}$ \\
\hline$F_{y}$ & $151.42 \mathrm{~N}$ \\
\hline$a$ & 0.127 \\
\hline
\end{tabular}

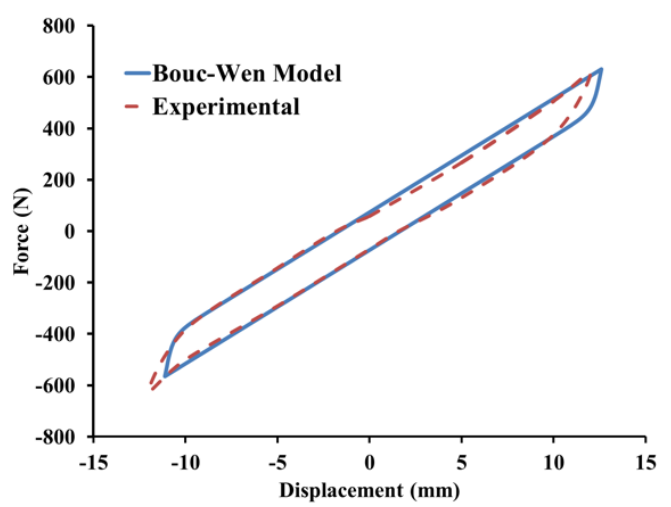

Fig. 2. Force-displacement curve of the WRI and its simulation using Bouc-Wen model.

\section{Case study buildings}

To assess the performance of wire rope isolators in protecting equipment against earthquake induced vibrations, we consider the eight-story structure shown in Figure 3, which is taken from Ismail et al. [6]. The equipment is mounted on a raised floor, which is connected to the $7^{\text {th }}$ floor through a wire rope isolator system. At this level, it is expected to have a strong amplification of seismic acceleration with strong component at long periods [6]. In this study, 36 WRIs were used to isolate the raised floor and equipment. The study has been conducted for the two cases: case (1) equipment fixed to the hosting floor (Figure 4(a)) and case (2) Equipment is mounted on an isolated raised floor (Figure 4(b)). The hosting structure is a reinforced concrete Moment Resisting Frame (MRF) modeled as a linear shear building. The nonlinearity is concentrated only at the isolation system level. For all structural vibration modes, a $2 \%$ of critical damping is considered. 


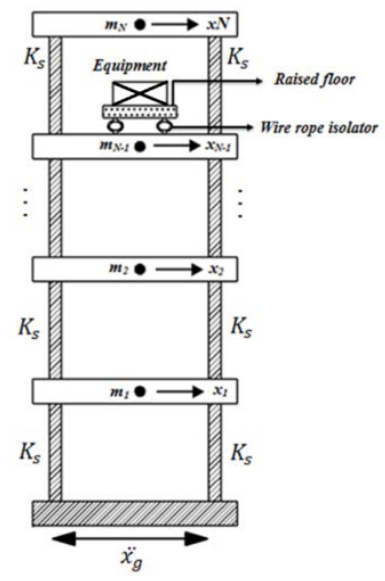

Fig. 3. Idealized structure with equipment mounted on the upper floor through raised floor approach.

The raised floor is modeled as rigid in the horizontal direction while the equipment is modeled as a linear single-degree of freedom system (SDOF) system with mass $m_{e}$, stiffness $k_{e}$ and damping $c_{e}$. The equipment's damping is equal to the structural damping. The effective isolation can be achieved by increasing the period of the isolated equipment to large values [8]. Accordingly, the equipment is designed to achieve a fundamental period of $0.03775 \mathrm{~s}$ when fixed and $1.35 \mathrm{~s}$ when isolated. Consistent with the work done by Ismail et al. [6], three example structures having different lateral stiffness matrices were also considered to study the influence of flexibility of the structure.
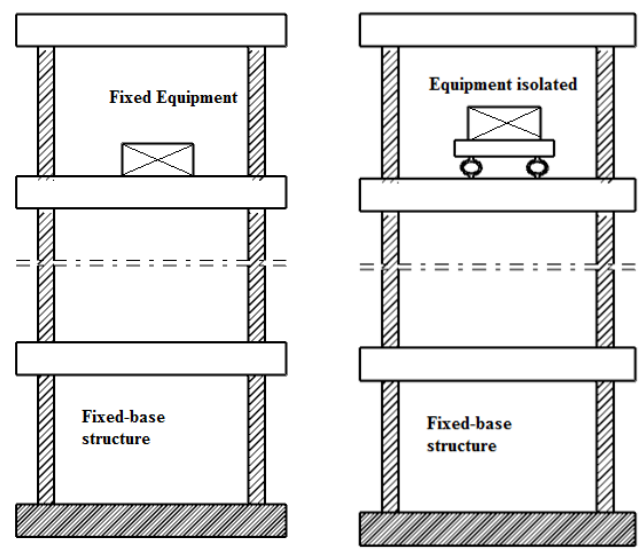

Fig. 4. (a) The case of fixed-base equipment; (b) the case of equipment isolated from the structure through WRI using raised floor approach.

\section{Numerical simulation models}

Nonlinear earthquake response history analyses (NLRHA) were performed for the structure and equipment using the structural analysis program SAP2000 ${ }^{\circledR}$. The super structure was modeled as a linear shear building with different lateral stiffness matrices $\left(0.5 K_{s}, K_{s}\right.$, and $\left.K_{5} 2\right)$ to study the influence of the superstructure flexibility on the performance of the seismic isolation system. A $2 \%$ damping ratio is assumed for all structural modes. The WRI 
is modeled in SAP2000 ${ }^{\circledR}$ as a nonlinear link (NL-Link) element having a behavior governed by the Bouc-Wen model of hysteresis (Plastic Wen) (see Section 2). The properties of the selected WRI along with its Bouc-Wen parameters were given in Table. 1. The simulation models were subjected to six different earthquake records. These records have been categorized based on the peak ground acceleration (PGA) to Peak ground velocity (PGV) ratio [20] as shown in Table 2. The NLRHA was performed for the two cases (fixed-base equipment and base-isolated equipment). The reinforced concrete MRF superstructure is an eight-story building having each story height and bay width, $3000 \mathrm{~mm} \times 5000 \mathrm{~mm}$ respectively. The cross sections of the columns and beams were modeled as $1000 \mathrm{~mm} \mathrm{x}$ $250 \mathrm{~mm}$ and $750 \mathrm{~mm} \times 250 \mathrm{~mm}$, respectively.

Table 2. Earthquake records used in the present study.

\begin{tabular}{|c|l|c|c|c|}
\hline Record\# & \multicolumn{1}{|c|}{ Earthquakes } & PGA (g) & PGA/PGV ratio & Class \\
\hline 1 & San Francisco California, 1957 & 0.085 & 1.67 & High \\
\hline 2 & Banja Luka Yugoslavia,1981 & 0.074 & 2.31 & High \\
\hline 3 & Kern County California,1952 & 0.179 & 1.01 & Intermediate \\
\hline 4 & Mexico City,1985 & 0.123 & 1.17 & Intermediate \\
\hline 5 & San Fernando California,1971 & 0.132 & 0.61 & Low \\
\hline 6 & Near E. Coast of Honshu, Japan,1968 & 0.226 & 0.68 & Low \\
\hline
\end{tabular}

\section{Results and discussion}

Considering first the case of the superstructure with a lateral stiffness $K_{\varsigma}$ and an equipment having a mass of $1 \%$ of the total structural mass. Figure 5 compares the equipment's peak acceleration and peak relative displacement for the two cases considered in this study. Figure 5(a) demonstrates the effectiveness of the WRI in reducing the equipment acceleration; the WRI isolation system can reduce up to $55 \%$ of the equipment acceleration on an average for all earthquake excitations. This reduction is mainly due to the reduced base shear force transmitted from WRI to the raised floor. The reduction in shear force is due to the decoupling offered by the nonlinear behavior of the WRI. A maximum reduction of $60 \%$ was observed for the Coast of Honshu 1968 earthquake record, which is categorized as high level.

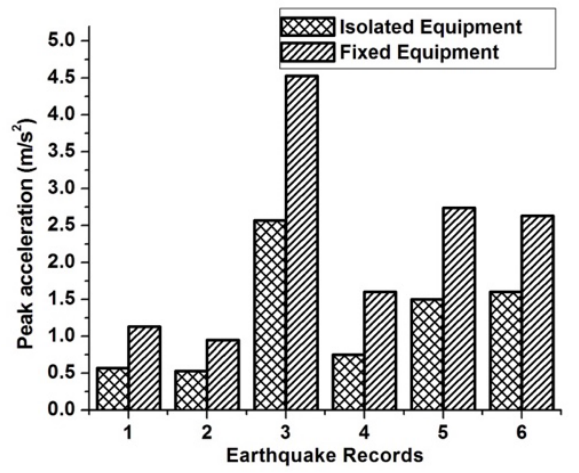

(a)

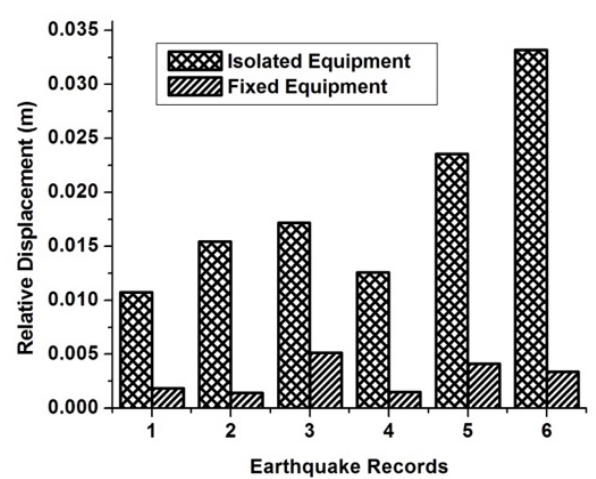

(b)

Fig. 5. (a) Peak acceleration and (b) and peak relative displacement response of the fixed-base and base-isolated structures. 
The decrease in acceleration is achieved at the expense of increased lateral displacement. Figure 5(b) shows the equipment's peak lateral displacement relative to the hosting floor under each earthquake excitation. This is a property of most passive isolation systems; the isolation system decouples the equipment from the structure resulting in a much larger lateral displacement. A maximum displacement of $35 \mathrm{~mm}$ was observed for the Honshu, Japan, 1968 earthquake, which can be due to the strong motion at lower frequencies close to the isolated equipment's frequency.

Figure 6 compares the relative displacement time history (between the equipment and the hosting floor) for the case of Mexico City 1985 earthquake. The figure shows that the WRI provides $46 \%$ reduction in the acceleration while maintaining an acceptable lateral displacement.

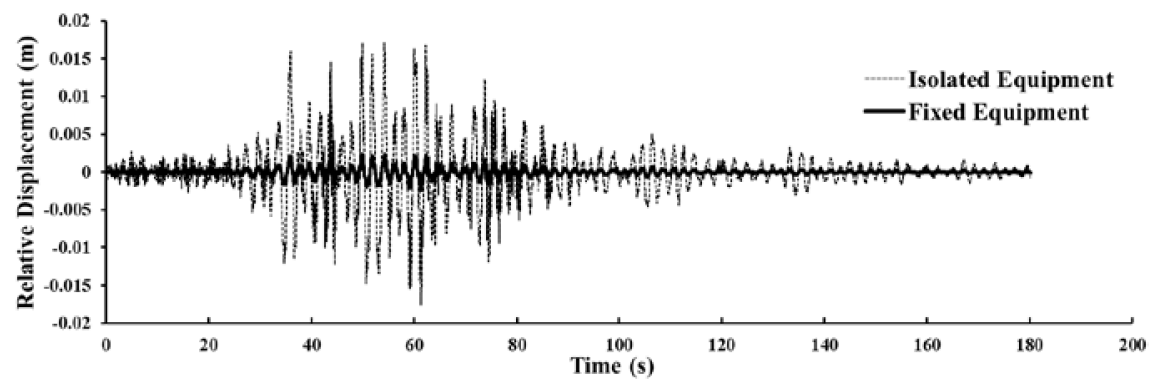

Fig. 6. Relative displacement time history of the equipment of the fixed and isolated equipment under Mexico City earthquake.

The influence of flexibility of the structure on the WRI performance is studied by simulating the response of the three structures having a lateral stiffness of $0.5 K_{s}, K_{\varsigma}$ and 2 $K_{\varsigma}$ subjected to harmonic base excitations having a magnitude of $0.5 . G$ and different frequencies ranging from $1 \mathrm{~Hz}$ to $20 \mathrm{~Hz}$.

The peak accelerations ratio between the fixed and isolated equipment under different harmonic frequencies are shown in Figure 7. The WRI was effective in reducing the acceleration even under harmonics having frequencies close to the structural dominant frequencies, which are $2.796 \mathrm{~Hz}$ for the $0.5 K_{s}, 3.664 \mathrm{~Hz}$ for the $K_{s}$, and $5.203 \mathrm{~Hz}$ for the $2 K_{s}$. For different harmonic base excitations, larger displacements of the equipment are observed in the most flexible structure (i.e., the $0.5 K_{s}$ ) (Figure 8). However, the WRI system could maintain the displacement of the equipment within an acceptable range for all excitation frequencies.

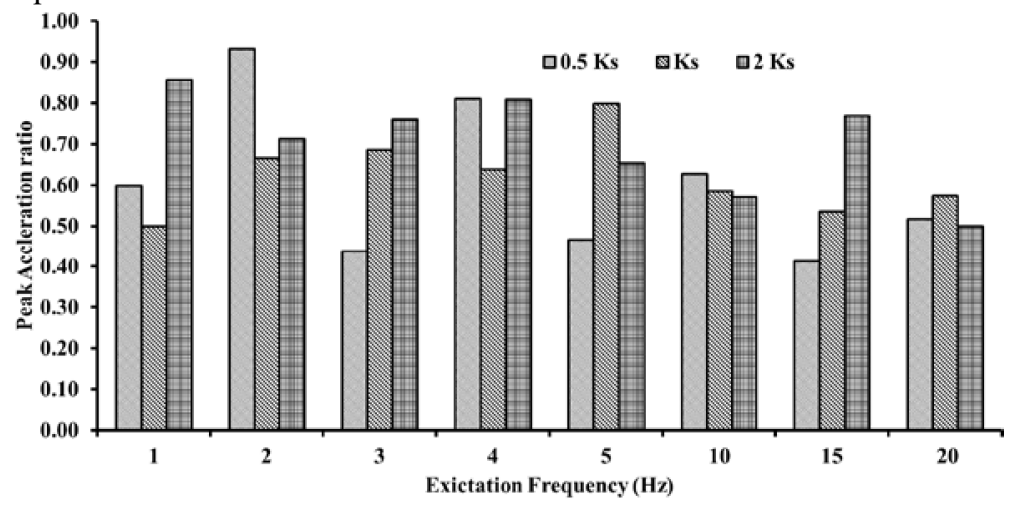

Fig. 7. Peak acceleration response under different harmonic base excitations. 


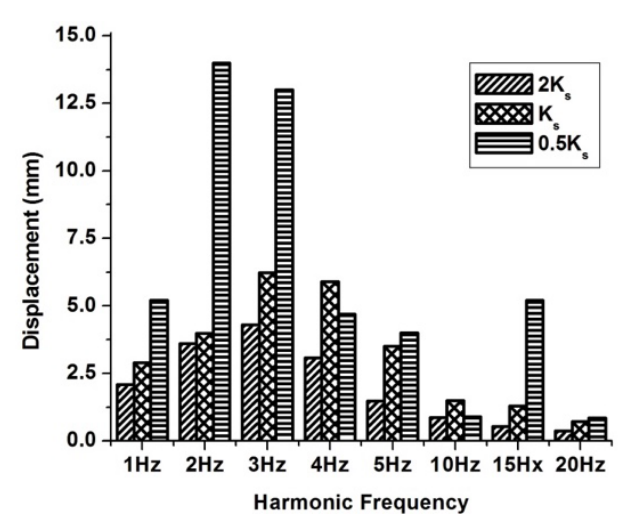

Fig. 8. Displacement response under different harmonic base excitations.

\section{Conclusions}

The present work investigated the performance of wire rope isolators (WRIs) in isolating equipment mounted on the upper floor of a moment resisting frame structure. It was shown that the WRI is effective in reducing the equipment acceleration, hence, minimizing structural damages. However, the lateral displacement of the equipment is larger in this case. In addition, the following conclusions are drawn:

1. WRI reduced the acceleration of the equipment by $55 \%$ on an average and a maximum of $60 \%$ reduction was observed for Honshu, Japan 1968.

2. The maximum displacement demand among the applied earthquake excitations is 35 $\mathrm{mm}$. Furthermore, the present simulation model also provides a way to determine the displacement demand required for the application and hence suitable WRI can be selected to provide the required displacement demand.

3. The WRI isolation system is effective and practically useful for different structures having different properties.

This study was partly funded by the SEED fund by the University of Sharjah. This support is highly appreciated.

\section{References}

1. J. Alanoly, S. Sankar, J. Mec Des-T ASME 109, 2 (1987)

2. R.A. Ibrahim, J. Sound Vib. 314, 3 (2008)

3. M. Ismail, J. Rodellar, F. Ikhouane, Struct Control Htlth 19, 1 (2012)

4. Rivin, Eugene I., Passive vibration isolation, New York, ASME press (2003)

5. M. Hamidi, M.H. El Naggar, Earthq. Eng. Struct Dyn. 36, 11 (2007)

6. M. Ismail, J. Rodellar, F. Ikhouane, J. Sound Vib. 326, 3 (2009)

7. F. Naeim, J.M. Kelly, Design of Seismic Isolated Structures: From Theory to Practice, Wiley, (1999)

8. G.F. Demetriades, M.C. Constantinou, A.M. Reinhorn, Eng. Struct 15, 5 (1993)

9. M. Ismail, J. Rodellar, G. Carusone, M. Domaneschi, L. Martinelli, Acta Mech. 224, 3 (2012)

10. D. Xu, Q. Yu, J. Zhou, S.R. Bishop, J. Sound Vib. 332, 14 (2013)

11. B. Ravindra, A.K. Mallik, J. Sound Vib. 170, 3 (1994) 
12. P. Paolacci, R. Giannini, "Study of The Effectiveness of Steel Cable Dampers for The Seismic Protection of Electrical Equipment," in Proc. 14th World Conference on Earthquake Engineering, Beijing, China (2008)

13. G. Massa, S. Pagano, E. Rocca, S. Strano, Meccanica 48, 7 (2013)

14. P. S. Balaji, M. Leblouba, Muhammad E. R., L. H. Ho, Mech Based Des. Struc. 44, 4 (2016)

15. P. S. Balaji, M. Leblouba, Muhammad E. R., L. H. Ho, J Mech Sci Technol. 30, 1 (2016)

16. P. S. Balaji, M. Leblouba, Muhammad E. R., L. T. Vuia, J Mech Sci Technol. 29, 4 (2015)

17. P. S. Balaji, M. Leblouba, Muhammad E. R., L. H. Ho, IOP Conf. Ser.: Mater. Sci. Eng.. 78, 1 (2015)

18. M. Leblouba, S. Altoubat, Muhammad E. R., P. S. Balaji, Shock Vib. 2015, ID 482063 (2015)

19. Y.K. Wen, J. App. Mech. 47, 1 (1980)

20. N. Naumoski, A.C. Heidebrecht, W.K. Tso, M.U.E.E.R. Group, "A Selection of Representative Strong Motion Earthquake Records Having Different A/V Ratios," McMaster University, Earthquake Engineering Research Group (1988) 